\title{
A Influência das Estratégias Promocionais das Indústrias Farmacêuticas sobre o Receituário Médico na Faculdade de Medicina de Marília: uma Visão Ética*
}

\author{
The Influence of Pharmaceutical Companies \\ Advertising Strategies on Medical Prescription \\ at the School of Medicine in Marilia, São Paulo, \\ Brazil: an Ethical Perspective.
}

Ciovarni Jose Dal Poggettes Molinari Buln Celso dos Santos Moreira? Lucieni de Clivi:ira Conterno ${ }^{3}$

PAIIVRASCHAVE

-Propaganda;

- Indúsiria framacéucicar

- Prescriçĩn de Mcdicamentus;

- Ética Médica

KE:Y-WORISS

- Adverusing,

- Drug Indusiry;

- Prescriptions, 1)rugi

- Ëihics, medical.

Recclsides ens: 14/07/2004 Recncaminhatelu cm: 11/11/2004 Recencaminhado ens: 10$) /(1) 3 / 2(x) 5$ Recricaminliado ens: 19/(14/2005 Aprovackecm: $11 / 05 / 2005$

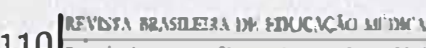

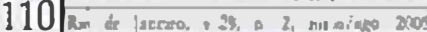

\section{RESUMO}

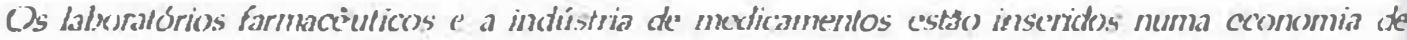

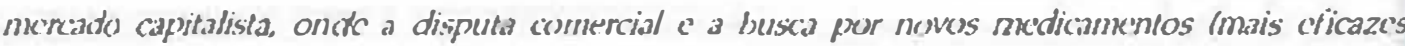

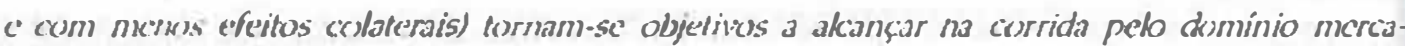

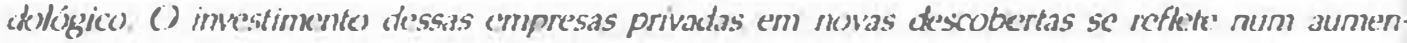
10 significantivo cm s'x custo. Se'm esse incentivo finamceiro. essas pesquisas cientílicas seriam

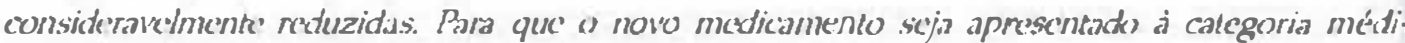

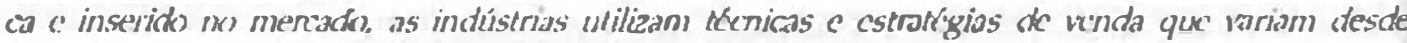

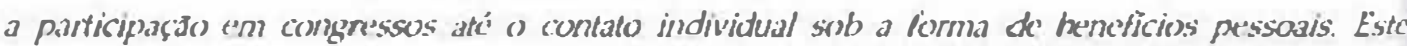

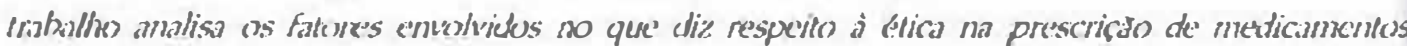

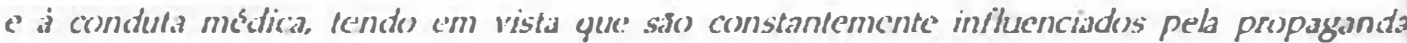
combercial, por vantagents concedictas e pela disterçaso de interesse's das partes convolvidas.

\begin{abstract}
Pharmaceutical compassies and the medical inchestsy as a nhok participalc in the capitalist marke' coenomy where commercial compclition and the search for me't drugs lwith gresaler

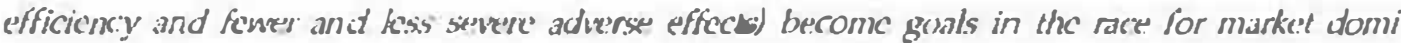
mance: Private companices investmernt in new discoverics results in at significant increase in the cost of drugs, Whilhout this financial incentive; such scicntific rescarch mould be: consicterably limiled. In order to prestent a men atrug to the nkxfical proficssion and laumb it in the market, pharmaceutical compasnic's use lechnique's and sale's stralcegies varving from participalion in metfical congresses; to individual contacts, in tik. form of pecrsonal lxeprestits giranterd (e) physicians 7\%k. current articke aims to amalyze the factors imshert in the ethics of imevical prescriptions and medicas behavior, influsenced by constant cosnmercial adverlising, bertefits, and distortions in inlerest: annengy llx' various partices:
\end{abstract}

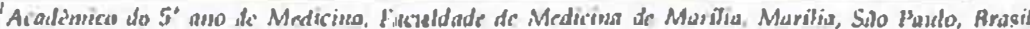

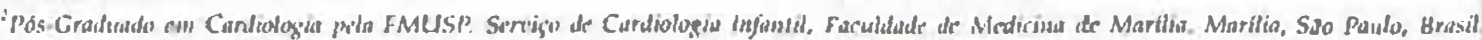

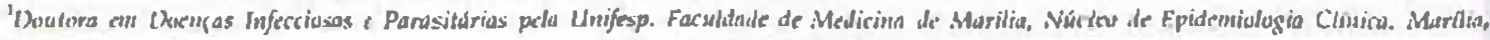
Sik l'uculo, Brasil. 


\section{INTRODUÇĀO}

\section{A Indústria liarmacêutica e a Produção de Medicamentos}

$\Lambda$ progressiva e constante alteração no perfil de saúdedocnça das populaçōes - caractcrizada pelo accimulo de doenças crônicas num mesmo paciente, no Hemisfério Norte e em algumas regiōes do Hemisfério Sul, e de grandes endemias e moléstias infecciosas, principalmente na Äfrica sub-Saara, associada ao aumento da longevidade nas regiôes deschvolvidas - demanda maiores e melhores intervengūes na área da sauide, em grande parte das vezcs, medicamentosas'.

Nesse contexto, um importante papel ć desempenhado pela pesquisa médica na área da química fina e do desenvolvimento de novas medicaçūes, sendou us laboratưrios impulssionados a procurar novos fármacos (com mellor eficácia terapêtutica c menor efeito colateral)2.

A geração de um novo medicamento ć um procedimento de alto custo - estimado entre US\$ 300 e 600 milhōes $^{2}$ - c no qual o tempo necessário para completar o processo gira cm torno de cinco a oito anos ${ }^{3}$. De lodas as moléculas que se investigan, uma ínfima proporçào chegará ao mercado $c$, desde o momento de sua patente até o de vencimento, a indústria terá que realizar todos os estudos clinicus $\mathrm{cm}$ diferentes fases que cond uzam à aprovação das au toridades sanitárias para sua comercializaçāo, recuperar scus investimentos c obter lucros, dado que suas patentes tên datas marcadas para vencer $2.4,5$.

Por vezes, este cenário se torna contraditório, refletindo. se na intenção de buscar o bem-cstar do pacienle por mcio do uso da razão e de fatos científicos, ao lado de técnicas, às vèes pouco éticas, relativas a questôes comerciais envolvidas na produção e venda de novos fármacos. O financiamento de novas pesquisas por empresas privadas se dirige fundamentalmente a enfermidades prevalentes no mundo industrializado c é, naturalmente, repassado ao custo do medicamento, de forma a compensar os gastos realizados nesses estudos ${ }^{2}$. Pela quase falência dos estados nacionais, submergidos numa crise sem precedentes nesses últimos 20 anos - quando procuraram se ajustar a um modelo de produção neoliberal e diminuíram de forma drástica sua capacidade de investimento em novas tecnologias -, a interrupçào desses investimentos no desenvolvimento de novas medicaçōes levaria a uma demora gigantesca na pesquisa de novos fármacos.

Oúltimo estágio da produçāo do medicamenlo ć o marketing, que implica um esforço maior que o da propaganda comum. Um dos setores que recebe maiores investimentos da industria ć o departamento de markeling, cujo papel é apresentar o medicamento à categoria médica c ao mercado, de forma que o produto pareça superior ao do concorrentes.
As empresas farmacêtuticas, em todo o mundo, lançam scus produtos sob denominaçōes arbitrárias, ditas "de fantasia ou de marca", após intensa propaganda que consome um percentual expressivo de seu faturamento. Mas se trata de uma peculiaridade que distingue esse de outros produtos industriais apenas pela intensidade.

O que coloca essa atividade industrial numa categoria especial éo fato de que o consumidor, que arca com as despesas, nāo é quem escolhe os produtos. Somente us médicos e decoradores usufruem desse privilégio?

Estima-se um gasto de US\$165 milhōes por ano nos Estados Unidos destinados à propaganda de medicamentos e cerca de US\$ 3,1 billōes com a força de vendas pessual, entre treinamento, salários e premiaçōes de representantes comerciais ${ }^{3}$. Apesar de tudo isto, do alto custo $\mathbf{c}$ da competitividade do mercado, a induistria farmacêutica é a mais rentável nos Estados Unidos'2. Por sc tratar de um país cujo mercado movimenta USS 58 bilhōes anualmente, a propaganda de medicamentos é um dos clementos diferenciais para vender mais ou menos um produto 6 . Já o mercado farmacêutico brasilciro cstá situado entre os dez maiores do mundo, e o valor do mercado brasileiro é quase o dobro do argentino ${ }^{3}$.

Como a diferença de efetividade dos fármacos entre si, testados para uma mesma situaçào, é cada vez menor, é preciso aumentar progressivamente o numero de estudos clinicos controlados e randomizados, assim como o mimero de pacientes envolvidos, o que leva a um crescimento exponencial dos custos que precedem o lançamento comercial de um novo produto, nem sempre verdadeiramente inovador?

\section{Promoção de Medicamentos Junto à Classe Médica}

Entende-se por promoção toda e qualquer atividade in. formacional e persuasiva pelos produtores e distribuidores, cujo cfeito ć ind urir a prescrição, suprimento, aquisiçāo c/ou uso de medicamentos*.

Todo apelo promocional em relação a medicamentos deverí ser seguro, preciso, confiável, informativo, balanceado, atualizado, capa\% de ser constatado e de bom gosto. Não deve conter desvios, afirmações nảo verificávcis ou omissões, bem como a induçâo do uso não justificável de medicamento. As comparaçiojes de produtus devem ser factuais, justas e comprováveis

O processo de promoçāo destinado ao médico é o que tem provocado mais problemas éticos ao utilizar métodos que the oferecem benefícios e podem lcvar a desvios do que seria umas prescrição correta².

Conforme comprovado em vários estudos, a propaganda consegue alterar o padrão de prescriçāo dos médicos, alćm 
de ser considerada a principal fonte utilizada por eles para atualização terapêtuticath.9.

l'ara promover o consumo de seus produtos, a industria utiliza a influencia por meio de visitadores, a publicidade nos meios de comunicação, a subvençào de ati vidades formativas, os benefícios promocionsis c os pagos de diferentes modos?

\section{Visitas de Representantes de Laboratórios (Propagandistas)}

Um representante clega a visitar, $\mathrm{cm}$ média, 15 mexlicos por dia, para distribuir traballıos cientificos, amostras grátis, brindes c visunl aid ${ }^{3}$. E a primeira fonte de in formação subre medicamentus mais frequientemente mencionada em pesquisas ${ }^{10}$.

Nlém de providenciarem informação, os representantes farmacêuticos se encontram numa posição em que podem empregar técnicas de influéncia para encorajar os médicos a mudar suas práticas de prescriçào"l.

\section{Patrocínio a Simpósios e Cungressos}

Os simpósios são úteis para disseminar informaçào. $O$ objetivo cientifico e o valor educacional podem ser acentuados se tais eventos forem organizados por corpos científicos ou profissionais ${ }^{*}$. No entanto, possuem uma parcela significativa de espaço e tempo para venda aos laboratórios ${ }^{8.12}$.

A WHO afirma que qualquer apoio a profissionais da sacide para participar em qualquer simpósio regional ou internacional não deverá ser condicionado a qualquer obrigação para promover qualquer produto ${ }^{8}$.

\section{Visual aid}

O visunl aid ć um material promocional que consiste num encarte com informaçỏes que destacam de mancira colorida c agradável as benceficios que o produto tem a oferecer ${ }^{12}$, além de compará-lo com os dos concorrentes por meio de gráficos ${ }^{3}$.

Considerando o possivel impacto destes panfletos e propagandas subre as práticas terapéuticas, espera-se que o material de propaganda tenha boa qualidade c forneça informaçōes importantes e confiás'eis sobre o proctuto anunciado8 a posologia, composiçào, referências, contra-indicaçòes, cuidados, adverténcias e reaçōes adversas, além de cumprir a lei que regulamenla a propaganda no Brasilo.

Estudos revelam que, no Brasil, as maiores deficiéncias desse material dizem respeito as informaçes sobre contraindicaçōes, cuidados, advertências c reaçōes adversas, $\mathrm{c}$ ìs referências. Além disso, na grande maioria dessas propagandas, o tamanho das letras é muito pequeno. Os argumentos visuais mais utilizados são recursos gráficus com superlativos e frases de impacto, que, em geral, discursam sobre eficácia, segurança, comodidade posológica, rapidez de ação c alta tolerabilidadent.

Tais propagandas visam mostrar ao médico detallıes sobre doença e terapêtutica - por vezes verdades fisiopatológicas, mas irrelevantes do ponto de vista da medicina baseada $\mathrm{cm}$ evidências - e buscam associar a prescrição de tal ou qual medicamento a tal poder e efetividade absolutamente incriveis e inscnsatos, pois não apenas consideram o produto indispensável no processo de saúde-doença, como o apresentam isento de riscos6.

\section{Oferecimento de Brindes e Auxílios}

Na opiniảo da WHO, a promoção sob a forma de beneficios financeiros ou materiais não deveria ser oferecida a profissionais da sacide para influenciá-los a prescrever medicamentos*.

Certamente, há um acordo universal em que não se cai em falta alguma quando se recebem subsidios de baixo custo ${ }^{3}$ - uma infinidade de itcns que trazem o nome comercial do produto e têm o intuito de promover a lembrança continuada do medicamento ao médico, con sua conseqüente prescrição ${ }^{3}$.

Por outro lado, também há consenso em que tal atitude é condenável quando o subsídio consiste $\mathrm{cm}$ viagens ou honorários para comparecer, como ouvinte ou expositor, a um cvento em que se faça propaganda aberta ou mais ou menos dissimulada de um produto farmacêuticu?2.

São notados diversos problemas éticos na aceitação destas colaboraçòes. O principal deles é o sentimento de divida gerado no médico quando recebe uma doaçảo? Esta relação de intercâmbio gera um modelo de reciprocidade equilibrada, onde o doador espera algo em troca, ainda que nào seja de imediato. Se nåo for assim, e nảo receber uma compensação reciproca, a relação social se fará tensa².

Negar a influência dos subsidios que se recebem sobre o comportamento é ser ingênuo. Serria acusar de ingenuidade também uma das ind ústrias mais poderosas do planeta quando emprega millhares e milhōes de privilégios promocionais se nāo obtivesse nada $\mathrm{cm}$ troca. A acei tação de seduçōes acarreta o risco de perder a objetividade nas decisỏes terapéuticas por obrigaçöes conscientes ou inconscientes².

\section{Distribuição de Amostras Grátis}

As amostras grátis são uma fração) do medicamento normalmente entregues à classe médica para que o produto seja avaliado ou mesmo lembrado, incrementando a prescrição?

São vistas como um recurso das companhias para introduzir um produto nov'o e cuja éficácia já está demonstrada, 
aprovado pelas autoridades sanitárias. São oferecidas ao médico em quantidades suficientes para tratamento de cinco a dez pacientes ${ }^{13}$

O Cremesp não considera atitude antiética o fornecimento gracioso de amostras aos pacientes que possam se beneficiar delas, porque isto atende ao disposto no Art. $2^{\circ}$ do Código de Ética Médica, segundo o qual o alvo de toda a atenção do médico é a saúde do ser humano ${ }^{14}$.

\section{Conflitos de Interesses}

Podemos definir "conflitos de interesses" como um conjunto de condiçōes em que o julgamento profissional relacionado a um interesse primário (como o bem-estar do paciente ou a validade da pesquisa) tende a ser definitivamente influenciado por um segundo interesse (como ganho financeiro). É uma condição e não um comportamento ${ }^{15}$.

A distribuição de informativos, amostras grátis, brindes e benefícios gerais aos médicos pelos laboratórios promove uma lembrança continuada e dá maior retorno em venda aos produtos lançados. Esta estratégia pode dar margem a distorçōes nas quais a colaboração pessoal com o médico torna-se mais importante que com o paciente ${ }^{2,16}$.

Uma relação estabelecida sobre as bases de um exercício profissional, como é a relação clínica, obriga, por um contrato implícito, a velar pelo interesse do paciente. Na conjuntura atual de fatores e de interesses econômicos na prática da medicina, é obrigatório recordar que os interesses dos pacientes precedem os das demais partes ${ }^{2}$.

O volume de recursos gastos com as diversas enfermidades gera uma grande pressão informativa da indústria farmacêutica sobre o médico, que tem de decidir que medicamento administrar ao paciente. A escolha entre diferentes opções, todas válidas, pode ter efeitos secundários médicos e econômicos muito diferentes e, portanto, também tem implicaçōes de caráter ético².

\section{A Política de Medicamentos no Brasil}

Atualmente, existem no mercado brasileiro três tipos de medicamentos em circulação: os de referência (inovadores ou de marca), os similares, que ainda utilizam denominação genérica, e os genéricos ${ }^{17}$.

O medicamento inovador ou de referência é aquele que apresenta em sua composição ao menos um fármaco ativo que tenha sido objeto de patente, mesmo já extinta. É registrado no órgão federal responsável pela vigilância sanitária e comercializado no país em que sua eficácia, segurança e qualidade tenham sido comprovadas cientificamente. Apresenta marca comercial ${ }^{17}$.
O medicamento similar com ou sem marca comercial surgiu no País após 1971, quando o Brasil decidiu não reconhecer as patentes de medicamentos. Corresponde àquele que contém os mesmos princípios ativos, as mesmas concentrações, as mesmas formas farmacêuticas, a mesma via de administração, a mesma indicação terapêutica e a mesma posologia, podendo diferir somente em características de tamanho, forma, prazo de validade, rotulagem e excipientes. Nunca foi obrigado a comprovar equivalência farmacêutica com o inovador ${ }^{17}$.

Os medicamentos genéricos são identificados pelo nome genérico da substância, segundo a Denominação Comum Brasileira ou Internacional (DCB e DCI). Conforme previsto na Lei $9.787 / 99$ ou "Lei dos Genéricos"18, corresponde ao equivalente terapêutico ante um medicamento de referência e que possui rigorosamente as mesmas características e efeitos sobre o organismo do paciente, sendo, portanto, intercambiável com o medicamento de referência. É produzido após expiração ou renúncia da proteção da patente ou de outros direitos de exclusividade ${ }^{17}$. Constitui um dos mais importantes avanços na consolidação da Política Nacional de Medicamentos, como estratégia fundamental para ampliar o acesso aos medicamentos e promover seu uso racional $^{19}$.

\section{Questões Éticas Envolvidas no Ato de Prescrever}

A prescrição de novos fármacos acaba por envolver não somente princípios farmacocinéticos, farmacodinâmicos, farmacotécnicos e farmacoeconômicos, como também a ponderação de fatores que possam influenciar a escolha médica nos receituários, prevalecendo os princípios éticos de não maleficência, beneficência e autonomia ${ }^{2,20,21}$. O primeiro, como pedra angular da ética médica, obriga a evitar fazer dano ao paciente com a prescrição; o segundo, a buscar seu maior benefício; e o terceiro, a acatar seu consentimento ${ }^{2}$.

A interpretação do que é ético varia em diferentes partes do mundo e em diferentes sociedades. A questão em todas as sociedades é o que se pode considerar um comportamento "adequado"в. Assim, o convívio da categoria médica com as indústrias laboratoriais em todos os níveis, desde a participaç̃o em congressos até o nível individual, é assunto delicado e importante para a sobrevida da conduta médica e do benefício dos pacientes, devendo ser abordado crescentemente nas discussões éticas.

Este estudo objetiva identificar e descrever as opiniôes dos médicos, colhidas por meio de um questionário sistematizado, sobre as possíveis relações entre a prescrição de medicamentos e a propaganda das indústrias farmacêuticas no Brasil. 


\section{MATERIAIS E MÉTODOS}

Realizou-se um estudo descritivo transversal de maio de 2003 a fevereiro de 2004. Foram entrevistados os médicos atendentes no Ambulatório de Especialidades "Mário Covas" da Faculdade de Medicina de Marília, ambulatórios de Psiquiatria, Saúde da Mulher e Saúde da Criança (Hospital de Clínicas Unidade II), Otorrinolaringologia (Hospital de Clínicas Unidade I) e Hematologia (Hemocentro). O ambulatório de Oftalmologia (Instituto de Olhos de Marília - IOM) não foi incluído porque os atendentes são médicos residentes e não assistentes da disciplina. A amostra distribui-se nas diferentes áreas médicas dentro da clínica cirúrgica, disposta em um grupo único e avaliada apenas uma vez.

A amostra é de conveniência, ou seja, não aleatória e não probabilística, usada intencionalmente ${ }^{22}$ para traçar o perfil dos profissionais atendentes no ambulatório que compõem o maior poder de emissão de receituários através da instituição.

Na coleta de dados foi aplicado um questionário não pontuativo, com perguntas fechadas e de alternativas. Para algumas perguntas não houve gabarito, ou a "resposta mais correta", abordando-se o tema da ética quanto a influência propagandista dos laboratórios, importância desta nos receituários e condições envolvidas no ato de prescrever.

Foram recolhidos 62 questionários do total de 89 médicos, entre docentes e assistentes, aplicados de setembro de 2003 a fevereiro de 2004. Um questionário não foi incluído no processamento estatístico por ter sido preenchido incorretamente.

A análise e o processamento dos resultados foram realizados por meio do programa Epi-info (versão 6). Foram considerados os testes estatísticos de $\div 2$ (qui-quadrado), IC $95 \%$ a um nível de significância $p<0,05$.

\section{RESULTADOS E DISCUSSÃO}

Obtivemos o retorno de $68,52 \%(61 / 89)$ dos questionários enviados aos médicos atendentes.

A presença do laboratório através do propagandista é vista como muito importante e importante por $9,80 \%$ e $47,50 \%$ dos médicos da Famema, respectivamente, enquanto $21,30 \%$ a consideram indiferente e dispensável.

$\mathrm{O}$ conceito de medicamento genérico foi corretamente respondido por $91,80 \%$, sendo que $8,20 \%$ tiveram respostas equivocadas. Os conceitos de medicamento similar e de referência tiveram uma porcentagem de acerto de, respectivamente, $77 \%$ e $78,70 \%$. Encontrou-se uma relação estatisticamente significativa entre o tempo de profissão e o conceito de genérico, de onde podemos inferir que os médicos formados recentemente (< 10a) e os com maior tempo de profissão (> 30a) não têm sedimentada a verdadeira definição desta classe de medicamentos. Essa diferença não deveria ser encontrada na população estudada, composta por médicos-docentes e assistentes de disciplinas, por se tratar de uma instituição de ensino médico que deveria estar sempre a par das políticas de saúde e pela divulgação intensa da mídia, após quase cinco anos de promulgação da Lei dos Genéricos (Lei 9.787 de 1999).

Entre os médicos da Famema, o auxílio de laboratório para comparecimento a congressos e reuniões científicas ocorre em $34,40 \%$. É neste nível medido e substancial que se espera que as colaborações ganhem maior influência no profissional médico e em sua conduta ao receitar.

Já o recebimento de brindes e benefícios em geral ocorre em $59 \%$ dos casos (Tabela 1). Há relação estatisticamente significativa entre o recebimento de brindes e de auxílio de laboratório para comparecimento a congressos $(\mathrm{p}<0,05)$, e, a nosso ver, os brindes são uma "porta de entrada" para colaborações mais expressivas. Não foi encontrada relação entre auxílio à classe médica pelos laboratórios e influência no receituário da instituição - apenas $4,80 \%$ admitiram que isto ocorre.

Ao receberem a colaboraçăo de um laboratório, apenas $5 \%$ sentem-se pressionados a prescrever o medicamento, ao passo que $36,70 \%$ gostam, porém dizem não ser influenciados; $1,70 \%$ gostam, pois acham que os brindes são interessantes e úteis. A grande maioria (55\%) sente-se indiferente, pois cada um estaria fazendo o seu trabalho.

Estes dados diferem do que se tem observado. Vários estudos sugerem que, na prática, o padrão do receituário sofre grande influência do laboratório, a tal ponto que em alguns países, como no Canadá, há orientaçōes para que os médicos não recebam brindes e que os laboratórios não patrocinem jantares para a promoção de medicamentos 23 .

Um comentário interessante em relação aos resultados obtidos é que diversas questões continham alternativas ou escolhas que poderiam ser consideradas politicamente corretas. Em outras palavras: espera-se que o profissional utilize fontes de informações cientificamente confiáveis, que consiga distinguir entre conteúdo e forma, e que se deixe orientar o mínimo possível pela propaganda. Dadas as características do estudo, não se pode assegurar que as respostas realmente reflitam a realidade. Os entrevistados podem não ter se sentido à vontade para explicitar comportamentos que não sejam bem-vindos ou aceitos na comunidade acadêmica.

TABELA 1

Relação entre recebimento de auxílio e de brindes oferecidos pelos laboratórios $(\mathrm{p}<0,05)$

\begin{tabular}{l|c|c}
\hline & Ganham brindes & Não ganham brindes \\
\hline Recebem auxílio & 16 & 5 \\
\hline Negam auxilio & 21 & 20 \\
\hline
\end{tabular}




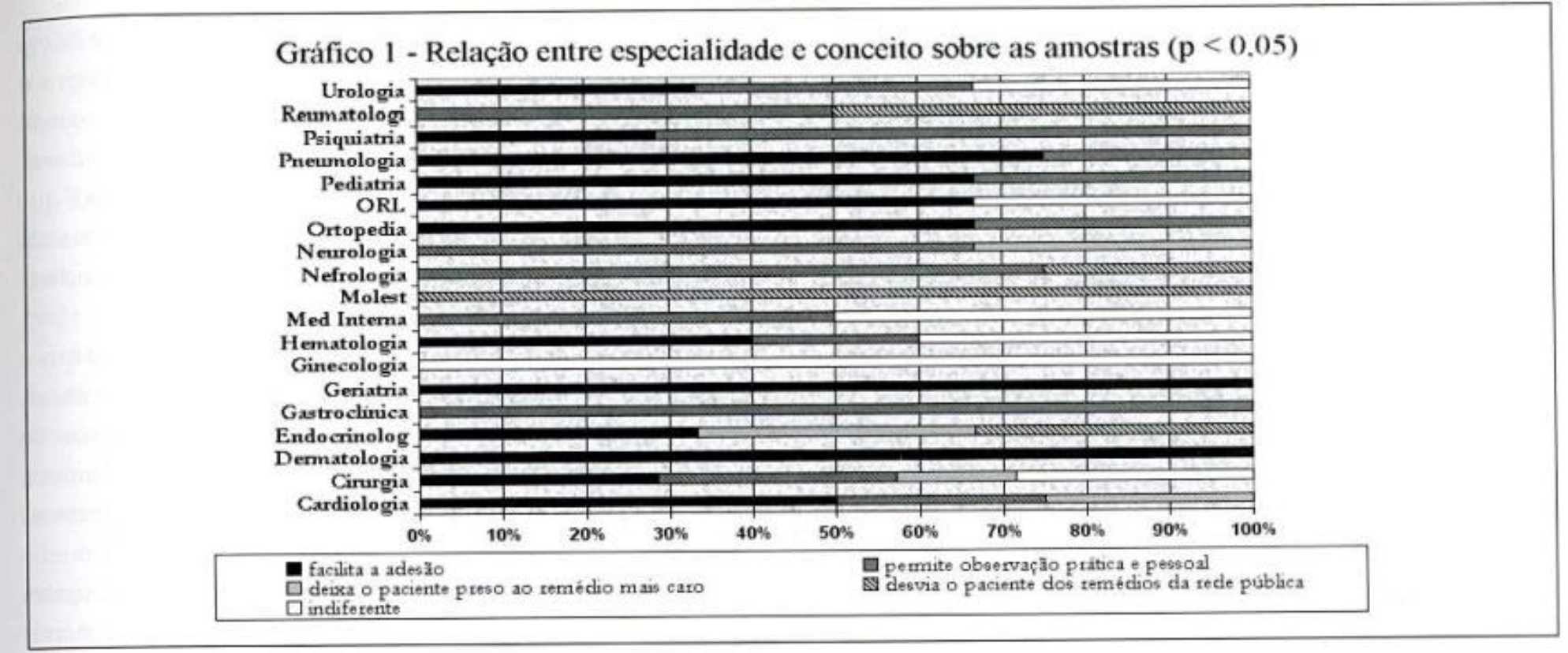

$\mathrm{Na}$ opinião dos médicos, as amostras grátis distribuídas pelos laboratórios facilitam a adesão do paciente em $37,70 \%$ dos casos, permitindo para $34,40 \%$ a observação prática e pessoal dos resultados; $6,60 \%$ acreditam que a amostra deixa $o$ paciente preso ao remédio mais caro, e igual número julga que desvia o paciente dos remédios disponíveis na rede pública; $14,80 \%$ são indiferentes. As áreas de gastrologia clínica, nefrologia, neurologia e psiquiatria afirmam, em sua maioria, que as amostras permitem a observação prática e pessoal, enquanto facilitam a adesão para as áreas de cardiologia, dermatologia, geriatria, ortopedia, otorrinolaringologia, pediatria e pneumologia $(\mathrm{p}<0,05)$ (Gráfico 1). Ainda sobre o uso de amostras, foi perguntado se ocorria uso pessoal ou familiar, tendo como resposta afirmativa $82 \%$.

Sobre a apresentação de laboratórios e novos medicamentos nos simpósios satélites em congressos, $61,70 \%$ dos entrevistados não se sentem influenciados, preferindo aprofundar os conhecimentos sobre a nova droga, e 3,30\% levam em consideração a influência exercida pelo laboratório. Em contrapartida, $5 \%$ e $8,30 \%$ sentem-se influenciados ora pela excelência das apresentações, ora pela projeção científica de renome dos palestrantes. Sentem-se indiferentes $21,70 \%$ (Gráfico 2). Observamos aqui o zelo pelo espírito crítico, não se chegando ao preconceito contra tais apresentações. Estes dados se relacionam em parte com os encontrados na literatura, onde $64 \%$ destacam que não há influência, contra $36 \%$ que reconhecem algum grau de influência. Sabe-se que, na grande maioria das vezes, o laboratório investe financeiramente em profissionais de renome para que estes demonstrem preferência pelo produto lançado ${ }^{3}$.

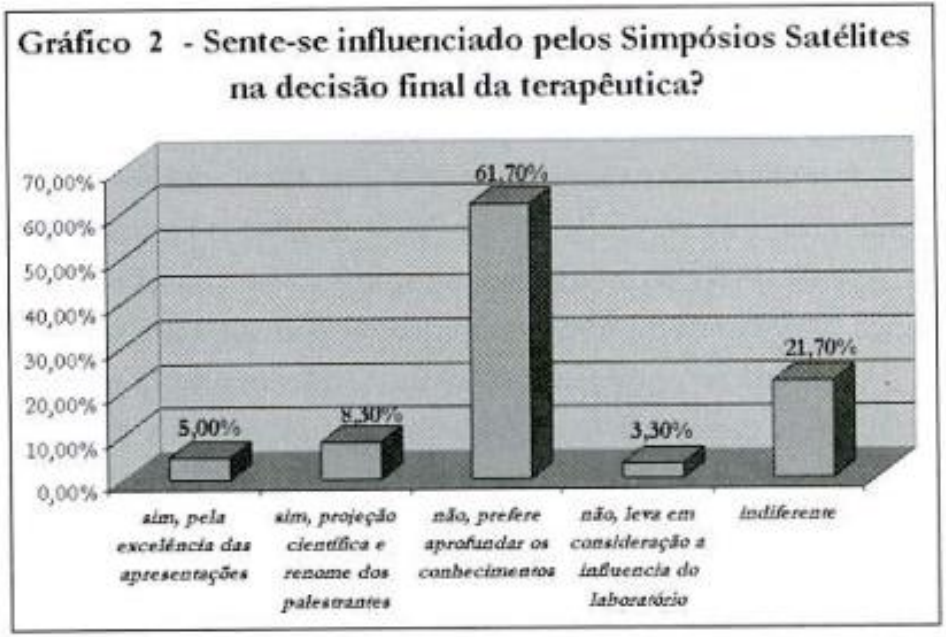

A prescrição final de medicamentos nos ambulatórios da Famema é avaliada em grande parte pelos entrevistados $(72,10 \%)$ como baseada em evidências, embora $32,80 \%$ prefiram receitar remédios disponíveis no serviço público de saúde,

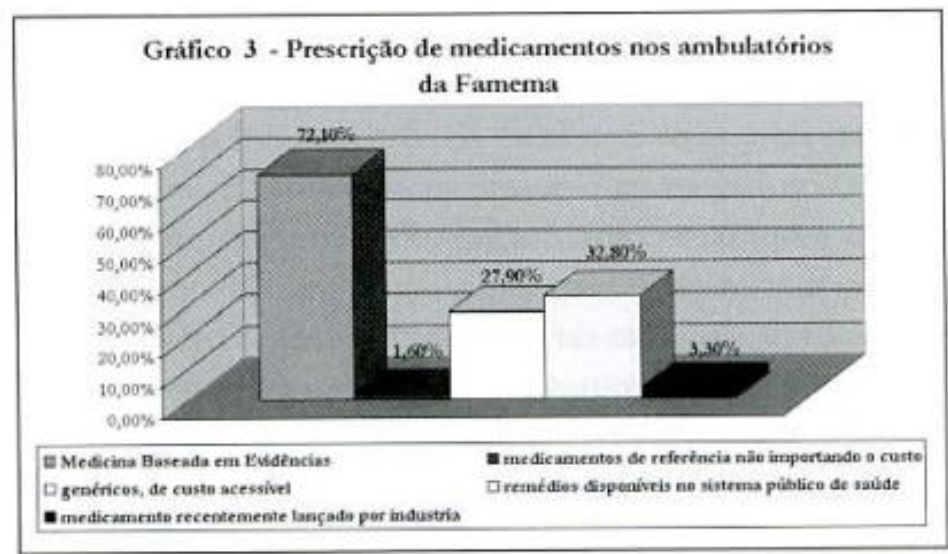


mesmo limitando um pouco o receituário. Os genéricos vêm em seguida com $27,90 \%$, sendo que cinco dos médicos que não os receitam (dos $72,10 \%$ ) desconhecem a sua definição. Em menor porcentagem ficaram os medicamentos de referência (não importando o custo) e os medicamentos recentemente lançados pela indústria, com 1,60\% e 3,30\% (Gráfico 3).

\section{CONCLUSÃO}

Os ambulatórios de especialidades da Faculdade de Medicina de Marília têm, em geral, um bom potencial no estímulo à venda de fármacos, uma vez que a demanda e o número de pacientes atendidos por semana são altos. No entanto, quase metade da população estudada não recebe os representantes da indústria farmacêutica ou recebe com freqüência muito baixa, menos de uma vez por semana nesta instituição.

Sendo assim, muito provavelmente, parte desses profissionais recebe os representantes comerciais dos laboratórios em outros locais de trabalho, como, por exemplo, nos consultórios particulares.

Pode-se pensar que a instituição serve de barreira a uma presença expressiva dos representantes, já que os docentes têm que dispensar tempo maior à assistência aos alunos e residentes, não restando tempo para receber o representante. Apesar disso, os médicos continuam a acreditar que a presença do laboratório através do propagandista é importante.

Os médicos entrevistados demonstraram ampla variabilidade nos conceitos teóricos sobre definições dos tipos de medicamentos no Brasil. Este é um achado importante, uma vez que, sendo docentes de uma instituição de ensino, esperava-se que estivessem a par das políticas de medicamentos no Brasil, tanto no surgimento das primeiras leis, quanto no desenrolar ao longo dos anos.

Quando perguntada sobre a ocorrência de auxílio financeiro de laboratório, recebimento de brindes e influência exercida no receituário, a maioria dos médicos nega sua ocorrência. No entanto, as influências na prescrição e no comportamento médico acontecem mais do que percebem ${ }^{10}$. As questôes sobre recebimento de brindes e de auxílios de laboratórios para comparecimento a eventos mostram números muito maiores do que os referentes à influência dos que o confessam. Os profissionais parecem ter dificuldades na avaliação de seu próprio comportamento ${ }^{10}$. Vale lembrar que os dados apresentados aqui podem representar um viés na resposta, em razão de tentarem ser mais socialmente aceitáveis ou reconhecerem que tal atitude, muitas vezes, é antiética, ou ainda por constrangimento em admitir qualquer influência.

O brinde oferecido pelas indústrias com marcas promocionais do produto promovido representa a "porta de entrada" e um facilitador do contato inicial entre o representante e o profissional prescritor. Uma vez estabelecida a confiança e o espaço para a colaboração mútua, colaborações mais significativas tendem a aparecer. Também é importante considerar, na cultura latina, a função do afeto interpessoal estreito, que de certa forma fideliza a prescrição a uma eventual amizade entre médico e representante laboratorial, tópico que deve ser mais bem entendido em pesquisas vindouras.

É senso comum e reconhecido entre a classe médica que a aceitação de brindes menores não é vista como falta de ética². Estranhamos que a avaliação ética sobre o recebimento de um presente dependa do valor material, pois não há limite a partir do qual se possa considerar antiético receber benesses.

Apenas uma pequena parcela dos médicos da Famema admite sentir-se pressionada a prescrever os medicamentos de laboratórios farmacêuticos, sendo que uma parcela menor teme não receitar marcas que os favoreceram com auxílios maiores.

Fica a reflexão: seria lícito receber auxílios para comparecer a eventos, ou aparelhos, receituários ou impressos sem que haja alguma contrapartida no receituário? Não seria mais leal rejeitar colaborações maiores? Se não tivessem retorno, os laboratórios - extremamente bem informados sobre as vendas de seu produto por região, por farmácia e até por receitas de cada profissional - insistiriam em distribuir vultosas benesses?

No que diz respeito ao uso de amostras grátis, mais da metade dos entrevistados as utiliza em seus pacientes e têm opinião favorável a seu respeito; as amostras são vistas como alternativas de tratamento e adesão, sendo bastante úteis para algumas especialidades entrevistadas. Apesar disso, o uso generalizado e muito antigo de amostras pelos médicos e seus familiares diretos (dependentes) faz com que julguem esse comportamento legítimo, e, desprovida de constrangimento, a maioria confessa a sua prática ${ }^{5}$. Entretanto, é evidente que as amostras grátis não se destinam a poupar as finanças dos médicos, mas a criar familiaridade com a prescrição de determinado medicamento.

Quanto a simpósios satélites e eventos promovidos diretamente por laboratórios, os profissionais reconhecem sua utilidade pela qualidade científica das apresentações e dos conferencistas, mas a maioria diz manter-se com grande espírito crítico, buscando confirmações e aprofundamentos posteriores.

Segundo a visão dos entrevistados, o tipo de medicação final prescrita nos receituários da Famema reflete a preocupação do profissional com a melhor conduta (medicina baseada em evidências) e sensibilidade em relação às questões sociais dos pacientes (genéricos e medicamentos disponíveis na rede 
pública de saúde). $O$ fator preço do medicamento influencia extremamente a tomada da decisāo, fazendo-se clara a demonstração de que está sensível à atual situação econômica dos brasileiros.

Os resultados sugerem que, curiosamente, os profissionais entrevistados se sentem capazes de se manter indiferentes aos favores e totalmente sem conflitos para receitar. Isto pode refletir a realidade idealizada e não a factual.

Muitos médicos acreditam que são imunes à influência comercial. No entanto, vários estudos mostram que aceitar presentes e hospitalidade da indústria farmacêutica pode comprometer o julgamento acerca da informação médica e a subseqüente decisão sobre o cuidado ao paciente ${ }^{23.24}$

Aqui talvez esteja o maior desencontro entre as expectativas (hipótese a priori dos investigadores) e os dados colhidos.

A maior parte dos profissionais de saúde, preocupada com a qualidade da assistência e das prescrições, possivelmente se espantaria com as respostas aqui colhidas, visto estarmos imersos, em grande parte das vezes, num contexto de práticas completamente inefetivas e ineficientes, ainda que por vezes eficazes.

Provavelmente, para nos aproximarmos mais da verdade, a metodologia das pesquisas qualitativas seria mais apropriada para entender esse aparente paradoxo e a distância entre a intenção e o gesto, a distância entre aquilo que eu creio ser correto fazer, faço e efetivamente penso que faço.

Outra face desse complexo problema é que, afora o agressivo projeto de marketing dessas indústrias, a propaganda de medicamentos esconde riscos em boa parte das vezes. Barros e Joany ${ }^{25}$ pesquisaram todos os anúncios das edições de agosto de 2000 a fevereiro de 2001 do Jornal Brasileiro de Pediatria, da Revista Brasileira de Medicina e do Jornal Brasileiro de Medicina. Das 1.774 páginas encontradas, 539 ( $30,4 \%$ do total) eram destinadas a anúncios, o que indica, inclusive, um alto grau de dependência econômica em relação aos laboratórios.

$\mathrm{Em}$ apenas $20 \%$ dessas propagandas havia informações sobre fatores que trazem riscos aos pacientes ${ }^{25}$. Não é preciso lembrar que isso freqüentemente acaba em tragédia, como ocorreu com a Fenfluramina (Isomeride $\left.{ }^{\circledR}\right)^{26}$ e mais recentemente com o Rofecoxib (Vioxx $\left.{ }^{\oplus}\right)^{27}$

A nosso ver, alguma estratégia poderia ser utilizada para melhorar esse cenário, sendo que as principais estariam associadas à educação médica e à regulação governamental do setor, de forma a responderem pelos excessos.

Desse modo, seriam estratégias privilegiadas para suporte aos médicos já formados a obrigatoriedade de explicitação de potenciais conflitos de interesses no desenvolvimento e publicação dos estudos, assim como o fomento público a pesquisadores bem treinados e que pacientemente desenvol- vam detalhada e criteriosa análise do desenho e condução dos estudos clínicos, fortalecendo cada vez mais a medicina baseada em evidências?

Para os médicos em formação, o quanto antes se introduzir no desenvolvimento do currículo médico a reflexão sobre os aspectos bioéticos concernentes à profissão, maior será a possibilidade de apreensăo e reflexão dos jovens acadêmicos nessa área. Isso aponta para um ensino de ética médica pulverizado pelas disciplinas e não mais concentrado numa apenas; não mais voltado para aspectos deontológicos, mas sim para o filosófico, sociológico e cultural no decorrer do curso e compromissado com a conjuntura sociopolítica em que estamos imersos 28

Em função disto, alguns países e organizaçōes profissionais, inclusive a Associação Médica Mundial, desencorajam uma relação muito próxima entre o médico e a indústria farmacêutica, e tentam estabelecer regras mais claras para esta relação ${ }^{23}$.

\section{REFERÊNCIAS}

1. Silva Filho CR. Qualidade de vida no climatério [dissertação]. São Paulo: Universidade Federal de São Paulo, Escola Paulista de Medicina; 1998.

2. Martino Moreno S. Ética de la prescripción. Conflictos del médico con el paciente, la entidad gestora y la industria farmacéutica. Med Clin (Barc) 2001; 116(8):299-306.

3. Carvalho KM, Teixeira RM. A influência de estratégias promocionais na adoção de novos produtos: o caso da indústria farmacêutica. Cad Pesqui Adm 2002; 9(1):61-74.

4. Geller M, Fernandes JT. The practice of pharmaceutical medicine in the United Kingdom. RBM Rev Bras Med 2001; 58(11):838-44.

5. Tan SY. Medicine and the pharmaceutical industry: what's right, what's wrong and what's to come. Singapore Med J 1998, 39(3):91-5.

6. Pizzol FDal, Silva T, Schenkel EP. Análise da adequação das propagandas de medicamentos dirigidas à categoria médica distribuídas no sul do Brasil. Cad Saúde Pública 1998; 14(1):85-91.

7. Silva Filho CR. Avaliação da qualidade de estudos clínicos controlados através do uso comparativo dos métodos de avaliação: de Maastricht, Jadad, Delphi e da Colaboração Cochrane [dissertação]. São Paulo: Universidade Federal de São Paulo, Escola Paulista de Medicina; 2003.

8. WHO. World Health Organization. Ethical criteria for medicinal drug promotion. Geneve; 1998 [cited 2003 Jul 27] Available from: http://www.who.int/medicines/library/ monitor/edm 17a.html 
9. Min LS. Como ter acesso à literatura médica. In: Drummond JP, Silva E. Medicina baseada em evidências: novo paradigma assistencial e pedagógico. São Paulo: Atheneu; 1999 p.61-87.

10. Drug Promotion Database [database on the Internet]. Geneve: WHO Department of Essential Drugs of Medicine Police; c 2002 [cited 2003 Jul 27]. Available from: http:// www.drugpromo.info

11. Roughead EE, Harvey KJ, Gilbert AL. Commercial detailing techniques used by pharmaceutical representatives to influence prescribing. Aust $\mathrm{N} \mathrm{Z} \mathrm{J} \mathrm{Med}$ 1998;28(3):306-10.

12. Vries TPGM, Henning RH, Hogerzeil HV, Fresle DA; OMS. Como manter-se informado a respeito dos medicamentos. In: Vries TPGM, Henning RH, Hogerzeil HV, Fresle DA; OMS. Guia para a boa prescrição médica. Porto Alegre: Artmed; 1998 p.85-92.

13. Moncada B, Acevedo-Oliva B. El médico y la industria farmacéutica. Gac Med Méx 1990; 126(4):343-7.

14. Cremesp. Consulta $n^{2} 57.662 / 99$, de 19 de outubro de 2001. Parecer: Presença de medicamentos na sala de consulta e se é permitido ao médico o fornecimento de amostras grátis aos pacientes. São Paulo; 2001 [Acesso em 2002 Set 10] Disponivel em URL: http://www.cremesp.org.br/legislação/pareceres/parcrm/57662_1999.htm

15. Thompson DF. Understanding financial conflict of interest. N Engl J Med 1993; 329(8):573-6.

16. Garber IL. Medicina: ciencia y humanismo: cuestionamientos y reflexiones de la práctica médica. Rev Invest Clin 2002; 54(4):366-75.

17. Cremesp, CRF-SP. Medicamentos Genéricos: informações para médicos, farmacêuticos e profissionais de saúde. São Paulo; 2001.

18. Brasil. Lei $n^{\circ}, 9787$, de 10 de fevereiro de 1999. Altera a Lei $n^{2} .6360$, de 23 de setembro de 1976, que dispõe sobre a vigilância sanitária, estabelece o medicamento genérico, dispões sobre a utilização de nomes genéricos em produtos farmacêuticos e dá outras providências. Brasília: Anvisa; 2003 [Acesso em 2003 Jul 27]. Disponível em: http:// www.anvisa.gov.br/hotsite/genericos/legis/ leis/ 9787.htm

19. Brasil.Ministério da Saúde. Conselho Nacional de Saúde. Resolução $n^{2} 280$, de 7 de maio de 1998. Brasília: Anvisa; 2003 [Acesso 2003 Jul 27]. Disponivel em http:// www.anvisa.gov.br/hotsite/genericos/legis/resolucoes/ 280_98cns.htm
20. Wall LL, Brown D. Pharmaceutical sales representatives and the doctor/patient relationship. Obstet Gynecol 2002; 100(3):594-9.

21. Santos y Vargas L. La professión de farmacia como una empresa moral. P R Health Sci J 2000; 19(2):169-74.

22. Fletcher RH, Fletcher SW, Wagner EH. Sumarizando. In: Fletcher RH, Fletcher SW, Wagner EH. Epidemiologia clinica: elementos essenciais. 3 ed. Porto Alegre: Artes Médicas; 1996 p. 256-72.

23. Coyle SL. Physician-industry relations: part 1: industrial physicians. Ann Intern Med 2002; 136(5):392-402.

24. Coyle SL. Relaciones entre los médicos y la industria farmacéutica. Arch Argent Dermatol 2002; 52(2):45-7.

25. Barros JAC, Joany S. Anúncios de medicamentos em revistas médicas: ajudando a promover a boa prescrição? Ciênc Saúde Coletiva 2002; 7(4):891-8.

26. Centro Brasileiro de Informações sobre Drogas Psicotrópicas - CEBRID. Drogas Psicotrópicas: efeitos adversos e novidades. Bol CEBRID [periódico online] 1998 mar [Acesso em 2004 Out 25];(32):[3 telas]. Disponivel em: http:// www.unifesp.br/dpsicobio/boletim/ed32/index.htm

27. Merck announces voluntary worldwide withdrawal of Vioxx. Whitehouse Station: Merck \& Co; 2004 [cited 2004 Out 25]. Available from: http://www.vioxx.com/vioxx/ documents/english/vioxx_press_release.pdf

28. Silva Filho CR, Conterno LO, Figueira EJG, Cazzo E, Tuma P. Apreensão de tópicos em ética médica no ensino-aprendizagem de pequenos grupos: comparando a Aprendizagem Baseada em Problemas com o modelo tradicional. Rev Assoc Med Bras 2004; 50(2):133-41.

\section{Apoio financeiro: Conselho Regional de Medicina do Estado de São Paulo.}

\section{Endereço para correspondência}

Giovani José Dal Poggetto Molinari

Rua Dr. Orozimbo Corrêa Neto, 65 - Bairro Santa Ângela 37701-268 - Poços de Caldas - MG e-mail: giovani@famema.br; gjdpm@uol.com.br

Paulo Celso dos Santos Moreira

Rua José Dias Molina, 375 - Jardim Tropical 17516-460 - Marília - SP

Lucieni de Oliveira Conterno

Rua José Camarinha, 467 - Bairro Maria Isabel

17516-220 - Marília - SP

e-mail: lucieni@famema.br 